\title{
Irinotecan and Capecitabine (CAPIRI) Plus Bevacizumab in First-Line Treatment of Metastatic Colorectal Cancer
}

\author{
Jose María Vieitez ${ }^{1}$, Paula J. Fonseca ${ }^{1}$, Jose P. Berros ${ }^{1}$, Miguel Fernandez de Sanmamed ${ }^{1}$, Eduardo Gutierrez \\ Restrepo $^{1}$, Marta Izquierdo ${ }^{1}$, Pablo Pardo ${ }^{1}$, Angel J. Lacave ${ }^{1}$ \\ ${ }^{1}$ Medical Oncology Service, University Central Hospital of Asturias \\ Correspondence: Dr. Jose María Vieitez, Medical Oncology Service, University Central Hospital of Asturias, \\ C/Celestino Villamil, S/N-33006-Oviedo, Spain. Tel: 34-606-366-149. E-mail: josemariavieitez@yahoo.es
}

\author{
Received: April 26, 2012 Accepted: May 9, 2012 Online Published: May 31, 2012 \\ doi:10.5539/cco.v1n2p25 URL: http://dx.doi.org/10.5539/cco.v1n2p25
}

\begin{abstract}
The purpose of this prospective study was to assess the efficacy and safety of bevacizumab in combination with reduced doses of irinotecan plus capecitabine (CAPIRI regimen), in patients with metastatic colorectal cancer (mCRC), as first-line chemotherapy. A cohort of $120 \mathrm{mCRC}$ consecutive patients was included. The overall response rate was $63.3 \%$ (76 patients; $95 \%$ confidence interval [CI], 53.97\%-71.77\%). Median time to progression and overall survival were 15 months (range: $2-49$ months; $95 \%$ CI: $13.00,17.00$ months) and 22.5 months (range: 4-54 months; 95\% CI: 21.00, 27.00 months), respectively. The one year survival rate was $81.5 \%$. CAPIRI-related grade $3 / 4$ adverse events included alopecia $(29.2 \%)$ and diarrhoea $(16.7 \%)$, which were manageable. Bevacizumab-related grade 3 hypertension was reported in 2 patients. One patient died due to treatment related adverse event, which was no bevacizumab-related. In conclusion, combination of bevacizumab plus CAPIRI is a feasible treatment which provides a clinical benefit as first-line treatment in chemonaïve patients with mCRC.
\end{abstract}

Keywords: irinotecan, capecitabine, bevacizumab, colorectal neoplasms, neoplasm metastases

\section{Introduction}

Approximately $60 \%$ of patients with colorectal cancer need chemotherapy to treat their metastatic disease. Chemotherapy was shown to increase the quality of life, time to disease progression (TTP) and overall survival (OS) of patients with metastatic colorectal cancer (mCRC). The introduction in recent years of new chemotherapeutic treatments (e.g. capecitabine, irinotecan, or oxaliplatin) or new regimens with monoclonal antibodies that inhibit specific molecular targets (e.g. bevacizumab, cetuximab, or panitumumab) have substantially improved the efficacy (Colucci et al., 2005; de Gramont. et al., 2000; Hurwitz et al., 2004; Simpson et al., 2003; Tournigand et al., 2004).

Capecitabine offers the advantage of continuous exposure to 5-FU without requiring central venous access (Cassidy et al., 2002; Van Cutsem et al., 2004) and, therefore, it is more convenient to administer, requires less hospitalization and decreases the utilization of medical resources (Payne, 1992). Capecitabine was developed, in combination with either oxaliplatin or irinotecan in a 3 week schedule, instead of 5-FU infusion, as an interesting alternative due to the practicality of the treatment. Moreover, the use of capecitabine instead of 5-FU, either with irinotecan or oxaliplatin, confirmed the activity and efficacy of the drug (Cassidy et al., 2004; Koopman et al., 2007). However, to date no study has shown which regimen (oxaliplatin based or irinotecan-based) is the best in the first and successive lines of treatment. In fact, two studies by Goldberg et al. (2004) and Tournigand et al. (2004) comparing oxaliplatin and irinotecan regimens found no differences in their survival rate and safety profiles. Likewise, studies comparing oxaliplatin and irinotecan regimens in combination with capecitabine were very scarce, as capecitabine doses used in initial comparative studies resulted in an unacceptable level of toxicity (Fuchs et al., 2008). Nevertheless, results from a phase II study by Grothey et al. found minimal differences in survival between capecitabine+oxaliplatin and capecitabine+irinotecan regimens (Schmoll et al., 2006).

In addition, it is important to avoid drugs with cumulative toxicity which can limit their benefits. For oxaliplatin-based regimens, severe peripheral neuropathy led to treatment discontinuation in more than $20 \%$ of patients after six months of treatment (Gamelin et al., 2002; Grothey, 2003; Krishnan et al., 2005). Moreover, $5 \%$ of the sensitive neuropathies were permanent or persisted for more than two years (de Gramont et al., 2000; 
Giacchetti et al., 2000; Hospers et al., 2006). On the other hand, the major adverse events (AEs) associated with irinotecan are diarrhoea and neutropenia, being not cumulative and allowing for continued treatment until disease progression.

New regimens with targeted drugs (e.g. bevacizumab) have shown to prolong the TTP as well. Bevacizumab, a humanized monoclonal antibody against vascular endothelial growth factor, combined with fluoropyrimidine based chemotherapy is one of the standard regimens in first line treatment of mCRC and has demonstrated a consistent benefit in several studies (Hurwitz et al., 2004; Macedo et al., 2012).

To gain further information on the efficacy and safety of bevacizumab in combination with reduced doses of capecitabine plus irinotecan (CAPIRI) in a 3-week schedule we decided to prospectively collect the data on this combination from a cohort of $\mathrm{mCRC}$ patients attending to our centre. The more favourable cumulative toxicity profile and convenience, made us prefer the low dose CAPIRI treatment in combination with bevacizumab over an oxaliplatin-based regimen. Reduced doses of irinotecan and capecitabine were chosen to increase compliance with the chemotherapeutic regimen while maintaining dose intensity within the activity range for these drugs (Kim et al., 2005). The low dose CAPIRI regimen is extensively used in our unit with acceptable tolerability, based on a previous phase I-II study with irinotecan in second line set conducted in our department (Vieitez et al., 2003). Here, we report the results of this non interventional, single-centre study.

\section{Method}

\subsection{Study Design}

The study was performed after obtaining approval from the local Institutional Review Board committee and in accordance with the Declaration of Helsinki, the Good Clinical Practices, and local ethical and legal requirements. The study was performed under standard clinical practice conditions in mCRC patients treated at the University Central Asturias Hospital in Spain. Before inclusion, all patients were fully informed about the study and all gave their written consent.

\subsection{Study Population}

Patients with histologically confirmed unresectable mCRC, with measurable lesions according to Response Evaluation Criteria in Solid Tumours (RECIST) (Therasse et al., 2000) by computed tomography (CT) scan; aged $\geq 18$ years and Karfnosky performance status (PS) $\geq 60 \%$ were included. Prior chemotherapy for advanced disease was not permitted, but adjuvant or neoadjuvant chemotherapy was allowed providing it was completed at least 12 weeks before inclusion. Prior radiotherapy was permitted if there were measurable lesions outside the radiation field at inclusion. Prior radiotherapy/major surgery must have been completed at least 6 weeks before inclusion. In the absence of symptoms (bleeding, obstruction, and perforation) patients without primary tumour resection or with ascites were eligible.

\subsection{Methods}

Patients received CAPIRI + bevacizumab treatment, which consisted of a 90 minutes IV infusion of irinotecan $240 \mathrm{mg} / \mathrm{m}^{2}$ on day 1 plus oral capecitabine $850 \mathrm{mg} / \mathrm{m}^{2}$ twice daily for 2 weeks plus bevacizumab $7.5 \mathrm{mg} / \mathrm{Kg}$ IV on day 1 in a 3 -week cycle. Delays or dose reductions for capecitabine (up to $40 \%$ ) or irinotecan (up to $20 \%$ ) were permitted according to the tolerance on previous cycle. Chemotherapy was continued until progression, death, unacceptable toxicity or refusal, or lost to follow-up.

The following information was collected from medical records at baseline visit: patients' medical history, Karfnosky PS assessment, and significant findings in blood and urinary tests (including proteinuria and CEA measurement levels). Data from tumour assessments performed were collected from baseline visit and, thereafter, every 2-3 months. The centre's standard clinical practice for tumour assessments includes CT evaluation of the chest, abdomen, and pelvis. Tumour responses were scored according to RECIST v1.0 criteria recommendations (Therasse et al., 2000). The safety was evaluated for all patients receiving at least one dose of the treatment cycle and graded according the National Cancer Institute Common Toxicity criteria (NCI CTCAE) version 2.

Complete liver metastatic resection with curative intention was attempted in patients who were deemed resectable after chemotherapy.

\subsection{Statistical Analyses}

The primary endpoint of this study was the overall response rate (ORR) assessment; i.e. the percentage of responders (complete response $[\mathrm{CR}]+$ partial response $[\mathrm{PR}]$ ) to treatment with CAPIRI + bevacizumab. The statistical software "Ene-2.0" (Badiella Busquets \& Pedromingo, 2010) was used to determine the needed 
sample size. Assuming a minimum efficacy of 44.8\% (the ORR reported by Hurtwitz et al (Hurwitz et al., 2004) for the IFL + bevacizumab group), a precision of $7.5 \%$, unilateral $\alpha=0.05$, and $\beta=0.20,119$ patients were required. Secondary endpoints included the evaluation of TTP, OS, and the safety profile.

Efficacy analyses included all treated patients. Safety analyses included all patients who received at least one dose of the treatment cycle. TTP was defined as the time from the date of signed informed consent to first documentation of disease progression. TTP was censored at the last tumour assessment or at the date of hepatic surgery for metastatic resection or treatment discontinuation without progression due to AEs. The Kaplan-Meier method was used to calculate the TTP and OS and to estimate the hazard ratio, median values, and $95 \%$ confidence interval (CI). A subgroup analysis [including age $(<70, \geq 70$ years); baseline Karnofsky PS (60\%, $>60 \%$ ); number of metastatic sites $(1,>1)$; baseline CEA (value in $\mathrm{ng} / \mathrm{ml}$ ); and KRAS mutation (wild type, mutation)] was performed to identify the effect of patient's baseline characteristics on response rate.

The final analyses were conducted 29 months after the last patient was included.

\section{Results}

\subsection{Patients}

Table 1. Baseline patient characteristics

\begin{tabular}{|c|c|c|c|}
\hline Patient characteristics & & Median (range) & n (\%) \\
\hline Age (years) & & $64(40-79)$ & \\
\hline \multirow[t]{2}{*}{ Gender } & Male & & $88(73.4)$ \\
\hline & Female & & $32(26.6)$ \\
\hline \multirow[t]{4}{*}{ Karnofsky } & 60 & & $27(23)$ \\
\hline & 70 & & $46(38)$ \\
\hline & 80 & & $39(32)$ \\
\hline & 90 & & $8(7)$ \\
\hline \multirow[t]{3}{*}{ KRAS gene status } & wild-type & & $64(53)$ \\
\hline & mutated & & $41(34)$ \\
\hline & unknown & & $15(13)$ \\
\hline \multirow[t]{3}{*}{ Primary tumour location } & Colon (except sigma) & & $33(27.5)$ \\
\hline & Sigma & & $42(35)$ \\
\hline & Rectum & & $45(37.5)$ \\
\hline \multicolumn{4}{|l|}{$\begin{array}{l}\text { Baseline metastatic disease } \\
\text { location }\end{array}$} \\
\hline & Liver & & $93(47.5)$ \\
\hline & Only Liver & & $45(37)$ \\
\hline & Nodes & & $36(18)$ \\
\hline & Lung & & $31(15.5)$ \\
\hline & Peritoneum & & $30(15)$ \\
\hline & Bone & & $3(1.5)$ \\
\hline & Others & & $5(2.5)$ \\
\hline CEA baseline value (ng/ml) & & $33(0.1-7589)$ & \\
\hline LDH baseline value (U/I) & & $381(218-1154)$ & \\
\hline \multirow[t]{4}{*}{ Prior treatment } & Tumour surgery (resection/derivation) & & $100(83.3)$ \\
\hline & Colon endoprosthesis & & $3(2.5)$ \\
\hline & Adjuvant or neoadjuvant chemotherapy & & $27(22.5)$ \\
\hline & Adjuvant or neoadjuvant radiotherapy & & $14(11.7)$ \\
\hline
\end{tabular}

Abbreviations: CEA: Carcinoembryonic antigen; LDH: lactate dehydrogenase 
The study included, between April 2005 and April 2008, 120 consecutive patients with mCRC treated at the University Central Asturias Hospital in Spain. Table 1 presents patients' baseline characteristics.

At the time of the study analysis (September 2010), 93 patients (77.5\%) had died. From the remaining alive patients, 9 patients continued on study treatment and the other 18 patients had discontinued study treatment due to disease progression and were receiving second or further lines of chemotherapy.

\subsection{Treatment}

The median number of cycles received was 19 cycles/patient (range: 3-42), with a total of 1872 treatment cycles. Median time from informed consent signature was 0 days (range 0-10).

Seventy five patients $(62.5 \%)$ required an irinotecan dose reduction and 65 patients $(54.2 \%)$ required a capecitabine dose reduction. However, during the first six cycles, only $10(8.3 \%)$ and $5(4.2 \%)$ patients required an irinotecan or a capecitabine dose reduction, respectively. The most frequent cause of dose reduction/interruption was grade $\geq 2$ diarrhoea for irinotecan and grade $\geq 2$ hand-foot syndrome (HFS) for capecitabine. Other causes of study dose reduction/interruption were neutropenia, mucositis, and thrombocytopenia. The median tolerated irinotecan dose in the first six cycles was $240 \mathrm{mg} / \mathrm{m}^{2}$ on day 1 every 3 weeks (100\% of the foreseen dose intensity [DI]), and was $192 \mathrm{mg} / \mathrm{m}^{2}$ if considering all cycles $(80 \%$ of foreseen DI). The median tolerated capecitabine dose in the first six cycles was $850 \mathrm{mg} / \mathrm{m}^{2}$ twice a day for 14 days every 3 weeks, and was $690 \mathrm{mg} / \mathrm{m}^{2}$ when all of the cycles were considered ( $80 \%$ of foreseen DI).

A total of 111 patients discontinued study treatment. Reasons for discontinuation were: disease progression in 93 patients, surgical resection of metastases in 10 patients, unacceptable AEs in 7 patients, and death due to arrhythmia which was not related to the study medication in 1 patient.

In total, $81(86.2 \%)$ out of the 93 patients with documented disease progression received subsequent chemotherapy, of which 30,34, 12, and 5 patients received two, three, four, and five additional lines of treatment, respectively. All these patients received oxaliplatin as second-line chemotherapy, most $(\mathrm{n}=66 ; 81.5 \%)$ in combination with capecitabine. Third line of treatment consisted of irinotecan in combination with cetuximab or panitumumab in wild-type KRAS patients.

\subsection{Efficacy}

All the 120 patients were evaluated for response. The ORR was $63.3 \%$ (76 patients; $95 \%$ CI: 53.97\%-71.77\%). A CR was observed in 3 patients (2.5\%) and a PR was observed in 73 patients $(60.8 \%)$. Stable disease was achieved in 36 patients $(30 \%)$ and disease progression was observed in the remaining 8 patients $(6.7 \%)$ with disease control in 112 (93.3\%). Higher response rates were achieved in younger patients $(64 \%$ vs. $60 \%$ for aged $<70$ and $\geq 70$ years, respectively), with better Karnofsky PS $(51.8 \%$ vs $66.6 \%$ for PS $\geq 60 \%$ and $<60 \%$, respectively) and with wild-type KRAS status (68.8\% with wild-type KRAS vs. $56 \%$ with mutant KRAS), although differences between groups were not statistically significant $(\mathrm{p}>0.05)$. 


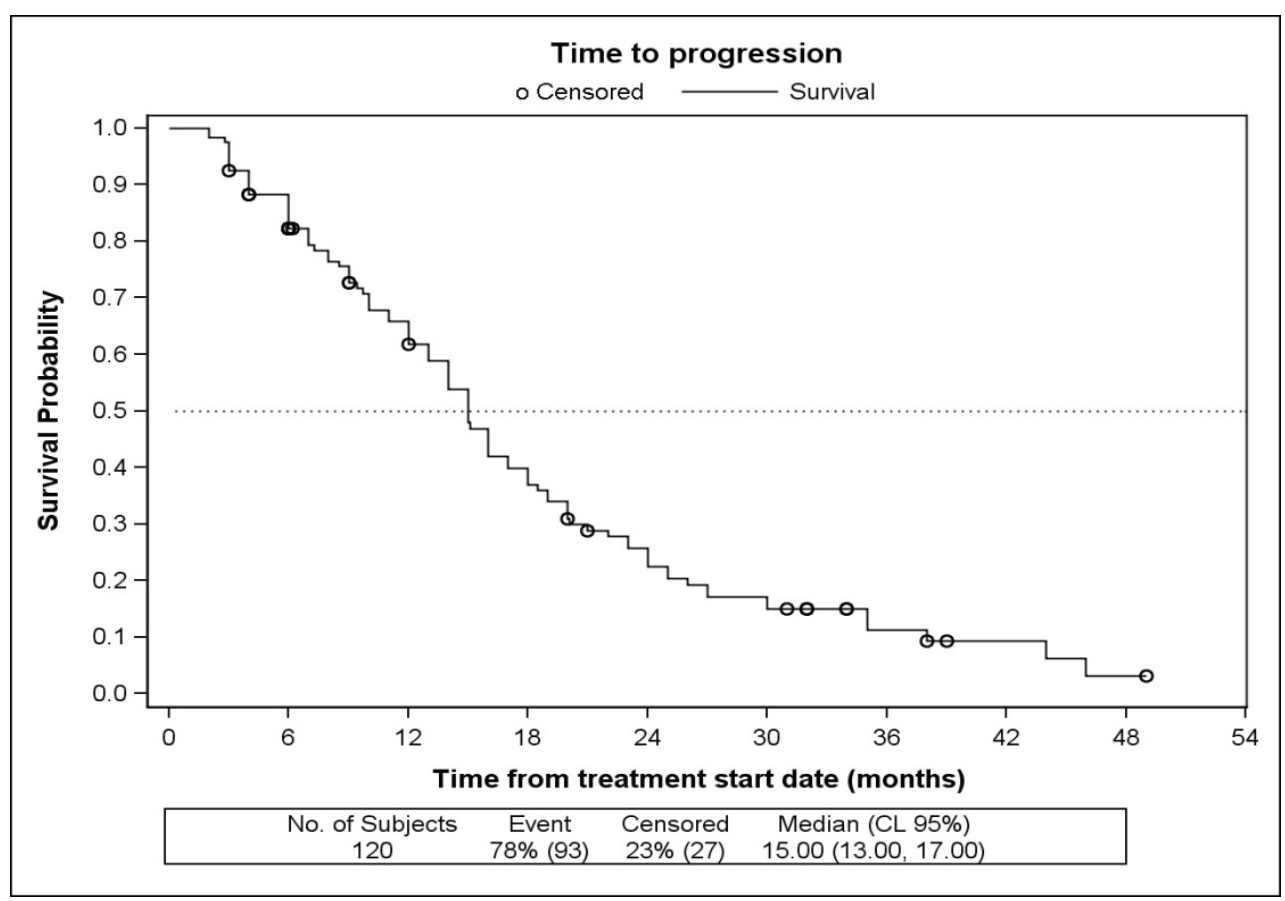

Figure 1. Kaplan-Meier estimates of time to progression

The median TTP was 15 months (range: 2-49 months; 95\% CI: 13.00, 17.00 months; Figure 1)

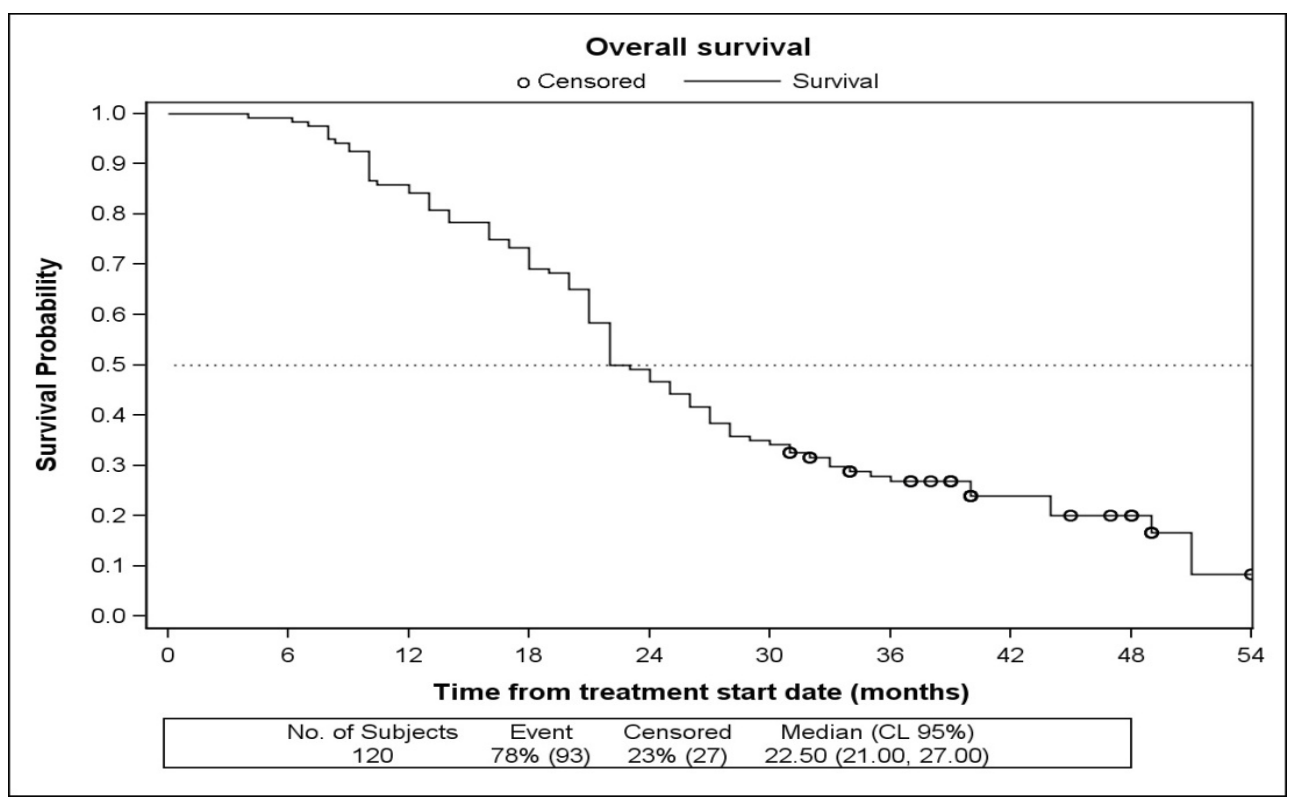

Figure 2. Kaplan-Meier estimates of overall survival

The median OS was 22.5 months (range: 4-54 months; $95 \%$ CI: $21.00,27.00$ months). The one year survival rate was $81.5 \%$.

\subsection{Liver Metastases Resection}

After a median of six cycles of chemotherapy (range: 4-9 cycles), complete liver metastatic resection with curative intention was attempted in $10(22.2 \%)$ out of the 45 patients with unresectable liver metastases at baseline.

The median length of postoperative hospitalization was 10 days (range, 8-29 days). R0 resection was feasible in all 10 patients. Survival rates at one and two year after surgery were $100 \%$ and $90 \%$, respectively. Two patients 
were disease-free at 38 and 46 months after surgery. Eight patients had recurrence after a median of 18 months (range: 6-43 months) following surgery. Wound healing postoperative complications prolonging hospitalization were reported in 2 patients. Both patients resumed study treatment.

\subsection{Safety}

Eighty nine patients $(74.17 \%)$ were reported to have at least one treatment related AE. In total, 508 different treatment-related AEs were documented, being the majority ( 427 out of $508 ; 84.1 \%$ ) with maximum CTC grade $\leq 2$. Table 2 summarizes the incidence of treatment-related AEs.

Table 2. Maximum CAPIRI-bevacizumab related AE per patient according to NCI-CTC grade $(\mathrm{n}=120)$

\begin{tabular}{|c|c|c|c|}
\hline NCI-CTCAE AEs & $\begin{array}{l}\text { Grade } 1 / 2 \\
\text { n (\%) }\end{array}$ & $\begin{array}{l}\text { Grade 3/4 } \\
\text { n (\%) }\end{array}$ & $\begin{array}{l}\text { All grades } \\
\text { n (\%) }\end{array}$ \\
\hline Alopecia & $42(35.0)$ & $35(29.2)$ & $77(64.2)$ \\
\hline Proteinuria & $75(62.5)$ & $0(0)$ & $75(62.5)$ \\
\hline Hypertension & $72(60.0)$ & $2(1.7)$ & $74(61.7)$ \\
\hline Hand-foot syndrome & $54(45.0)$ & $2(1.7)$ & $56(46.7)$ \\
\hline Hemorrhagic events (bleeding/epistaxis) & $51(42.5)$ & $4(3.3)$ & $55(45.8)$ \\
\hline Diarrhoea & $35(29.2)$ & $20(16.7)$ & $55(45.8)$ \\
\hline Neutropenia & $32(26.7)$ & $8(6.7)$ & $40(33.3)$ \\
\hline Febrile neutropenia & - & $3(2.5)$ & $3(2.5)$ \\
\hline Vomiting & $16(13.3)$ & $2(1.7)$ & $18(15.0)$ \\
\hline Mucositis & $16(13.3)$ & $0(0)$ & $16(13.3)$ \\
\hline Acute cholinergic syndrome & $16(13.3)$ & $0(0)$ & $16(13.3)$ \\
\hline Anaemia & $7(5.8)$ & $0(0)$ & $7(5.8)$ \\
\hline Thromboembolic events & $5(4.2)$ & $2(1.7)$ & $7(5.8)$ \\
\hline Thrombocytopenia & $3(2.5)$ & $0(0)$ & $3(2.5)$ \\
\hline Wound-healing events & $2(1.7)$ & $0(0)$ & $2(1.7)$ \\
\hline Hyperbilirubinemia & $1(0.8)$ & $0(0)$ & $1(0.8)$ \\
\hline Febrile neutropenia & - & $3(2.5)$ & $3(2.5)$ \\
\hline Total & 427 & 76 & 508 \\
\hline
\end{tabular}

Abbreviations: NCI-CTCAE $=$ National Cancer institute Common Toxicity Criteria. Some patients reported more than one AE.

The most common $(>20 \%)$ treatment-related AEs of any grade were alopecia $(\mathrm{n}=77,64.2 \%)$; proteinuria $(\mathrm{n}=75$; $62.5 \%)$, hypertension $(n=74 ; 61.7 \%)$; HFS $(n=56,46.7 \%)$, diarrhoea $(n=55,45.8 \%)$, hemorrhagic events $(n=55$; $45.8 \%)$, and neutropenia $(n=40,33.3 \%)$. A total of 43 patients $(35.8 \%)$ experienced grade $3 / 4$ AEs, the most common being alopecia $(29.2 \%)$ and diarrhoea (16.7\%). Diarrhoea episodes were resolved after subsequent dose reduction, or treatment cycle delay.

HFS was generally rated as grade $1 / 2(96.4 \%$; 54 out of 56$)$; none of the patients had grade $\geq 2$ HFS prior to the fifth cycle. Similarly; hypertension, proteinuria, and epistaxis $(n=51 ; 42.5 \%)$ were most of grade $1 / 2$. Grade 3 hypertension was reported in only two (1.7\%) patients. Sixty-six out of $74(89 \%)$ patients with previous pharmacologically controlled hypertension presented additional episodes of hypertension, which were overall manageable with antihypertensive medication (angiotensin-converting-enzyme inhibitors, diuretics, or calcium-channel blockers). No arterial thrombotic events were reported in the seven patients with previous venous or arterial history (all of them used prophylaxis anticoagulation doses during the study). No relevant AEs were reported for any of the 21 patients (17.5\%) with baseline ascites. There were no bevacizumab related episodes of gastrointestinal perforation or AEs leading to death. One or more cycles of bevacizumab were delayed because of toxicity in 15 patients [hypertension $(n=2)$, thromboembolic events $(n=7)$, hemorrhagic 
events $(n=4)$, and wound-healing complications $(n=2)]$ and bevacizumab was reintroduced in 13 of them without further complications. Lung thromboembolism was reported in 2 patients for whom bevacizumab treatment was discontinued as per investigator decision despite the event resolution.

Six patients $(5 \%)$ discontinued treatment due to treatment-related AEs, 5 of which were considered life threatening: febrile neutropenia leading to death in one patient, lung thromboembolism in two patients and, grade 4 diarrhoea with secondary renal insufficiency and dehydration in two other. The sixth AE leading to discontinuation was a grade 3 hypertension not manageable with oral antihypertensive treatment. One patient was hospitalized due to an opiate intoxication not related to study treatment but for which study treatment was firstly delayed and finally discontinued.

A total of 93 deaths were reported during the study, of which 91 were due to disease progression and two as a result of an $\mathrm{AE}$ which was considered treatment-related in one case. This latter was due to febrile neutropenia and occurred during the first 60 days of treatment. None died as a result of progressive disease in the first 90 days.

\section{Discussion}

The present observational study provides good evidence of the efficacy and good tolerance of the addition of bevacizumab to a reduced dose of CAPIRI in a 3-week schedule for the treatment of patients with mCRC in the first-line setting.

The efficacy results support the adequacy of the CAPIRI low dose regimen (irinotecan dose intensity of 80 $\mathrm{mg} / \mathrm{m}^{2}$ per week) in combination with bevacizumab with an ORR (63.3\%), TTP (median 15 months) and OS (median 22.5 months) which are consistent with those reported in other studies with CAPIRI at low doses plus bevacizumab (Ardavanis et al., 2008; Moehler et al., 2009). Moreover, median OS observed in our study was among the range of OS rates (22.5-25.1 months) reported with FOLFIRI (irinotecan dose intensity of $90 \mathrm{mg} / \mathrm{m}^{2}$ per week) regimen plus bevacizumab (Sobrero et al., 2009) or with bevacizumab plus other routine first-line chemotherapy regimens (Grothey et al., 2008; Van Cutsem et al., 2009).

Although a comparison of results from different phase studies can be only speculative, the efficacy of our schedule is in line with that obtained with oxaliplatin-based regimens combined with capecitabine with/without bevacizumab such as the TREE-2 phase II study (Hochster et al., 2008) or the NO16966 phase III study by Saltz et al. (2008) that showed lower response rates ( $46 \%$ and $49 \%$, respectively) but a similar survival rate ( 24 and 21.3 months, respectively).

Recent studies on the integration of capecitabine-based regimens with other biologic agents (such as cetuximab) had yielded similar efficacy rates as well. A recent randomized phase II study (AIO KRK 104) in first-line treatment of mCRC found an ORR of $46 \%$ for CAPIRI plus cetuximab versus $48 \%$ for CAPOX plus cetuximab (Moosmann et al., 2011). The lack of an external control of the radiologic evaluations in our study might partly explain the good results observed in our study. In a recent single-institutional open-label phase II study of irinotecan in combination with capecitabine (XELIRI) plus bevacizumab an ORR of $67.4 \%$, a median PFS of 12.3 months, and a median OS of 23.7 months was found (Garcia-Alfonso et al., 2010).

Different fluorouracil-based treatment regimens with irinotecan have been previously evaluated, and have overall shown a more favourable cumulative toxicity profile and convenience with low doses of CAPIRI (Cartwright et al., 2005; Kim et al., 2005; Park et al., 2004). However, the optimal dosing of CAPIRI has not been fully established. Two international studies (BICC C and EORTC 40015) using high doses of irinotecan $\left(250 \mathrm{mg} / \mathrm{m}^{2}\right)$ plus capecitabine $\left(2000 \mathrm{mg} / \mathrm{m}^{2}\right.$ daily for 14 days) given 3-weekly (XELIRI) resulted in an unacceptable level of toxicity (Fuchs et al., 2008; Kohne et al., 2008). Later studies with CAPIRI at lower doses (capecitabine $800-1000 \mathrm{mg} / \mathrm{m}^{2}$ twice a day for 14 days and irinotecan $200-240 \mathrm{mg} / \mathrm{m}^{2}$ IV on day 1 every 3 weeks) (Cartwright et al., 2005; Kim et al., 2005; Park et al., 2004), obtained a therapeutic activity similar to that observed with FOLFIRI as well as an acceptable safety profile, particularly when bevacizumab was added to the regimen (Ardavanis et al., 2008; Moehler et al., 2009). In fact, doses as low as $800 \mathrm{mg} / \mathrm{m}^{2}$ twice a day for capecitabine and $200 \mathrm{mg} / \mathrm{m}^{2}$ for irinotecan have been proposed as a starting point for future trials based on the regional differences observed in a review of previous studies with capecitabine-irinotecan regimens (Cartwright et al., 2010). Our regimen with little higher doses produces acceptable efficacy with manageable toxicities for most patients. Moreover, lower starting doses of irinotecan and capecitabine can be considered, since in those patients requiring dose reduction of irinotecan $(62.5 \%)$ and capecitabine $(54.2 \%)$ the proportion of objective responses was high. 
Overall, the safety profile of bevacizumab in combination with irinotecan reported in our study is consistent with that observed in previous clinical studies. (Kozloff et al., 2009; Nalluri et al., 2008; Scappaticci et al., 2007; Scartozzi et al., 2009; Van Cutsem E. et al., 2009). The administration of irinotecan every 3 weeks did not seem to increase the toxicity. In our study a slightly higher incidence of proteinuria, hypertension, and grade 1 bleeding was observed in patients receiving bevacizumab for more than one year. However, a low incidence of grade 2/3 bevacizumab-related AEs and no bevacizumab-related gastrointestinal perforations, grade 4 AEs, or AEs leading to death were seen. Furthermore, bevacizumab did not significantly increase the occurrence of CAPIRI AEs. Moreover, a metaanalysis (Golfinopoulos et al., 2007) of 242 studies in a total of 56,677 patients substantiates the use of irinotecan based regimen plus bevacizumab as first line treatment with a significant improvement in survival when this regimen was used (it was estimated a 8 months prolongation of the absolute survival benefit) which was higher than the benefit obtained with the oxaliplatin based regimen plus bevacizumab as first line treatment (4.7 months of survival prolongation).

In our study, bevacizumab plus CAPIRI allowed potentially curative resection in 10 out of the 45 patients $(22.2 \%)$ with unresectable hepatic metastases at the time of diagnosis that were deemed resectable after chemotherapy. This percentage of liver resections was similar to other studies (Okines et al., 2009; Van Cutsem et al., 2009; Yoo et al., 2006).

This prospective non-interventional study was performed in one site, which constitutes one important limitation. However, our unselected population based study included $23 \%$ patients with Karnofsky $60 \%, 16.6 \%$ patients $>70$ years and $17.5 \%$ patients with ascitis who are usually excluded in clinical trials but which is a representative sample of what is seen in common clinical practice (Hutchins et al., 1999). In addition, the possibility of investigator bias must be always considered due to the nature of the study; non-interventional, single arm, open label and non-randomised. In our study, the lack of a control group for comparison constitutes another study limitation and leaves a room for further improvement.

\section{Conclusion}

In summary, this study provides evidence of the clinical benefit of bevacizumab, when combined with CAPIRI at low doses, in chemonaïve patients with stage IV colorectal cancer treated in a common clinical practice setting. The use of capecitabine instead of 5-FU infusion can reduce the number of visits to day hospital, while the use of irinotecan instead of oxaliplatin as first-line treatment will possibly avoid the cumulative oxaliplatin doses, thus, reducing neurotoxicity throughout the disease course.

\section{References}

Ardavanis, A., Kountourakis, P., Mantzaris, I., Malliou, S., Doufexis, D., Sykoutri, D., ... Rigatos, G. (2008). Bevacizumab added to the irinotecan and capecitabine combination for advanced colorectal cancer: a well-tolerated, active and convenient regimen. Anticancer Res., 28, 3087-3092.

Badiella Busquets, L., \& Pedromingo, A. (2010). Ene-2.0. Cálculo del Tamaño Muestral. Retrieved from www.e-biometria.com

Cartwright, T., Lopez, T., Vukelja, S. J., Encarnacion, C., Boehm, K. A., \& Asmar, L. (2005). Results of a phase II open-label study of capecitabine in combination with irinotecan as first-line treatment for metastatic colorectal cancer. Clin Colorectal Cancer, 5, 50-56. http://dx.doi.org/10.3816/CCC.2005.n.016

Cartwright, T., McCollum, D., \& Boehm, K. A. (2010). Dosing considerations for capecitabine-irinotecan regimens in the treatment of metastatic and/or locally advanced colorectal cancer. Am. J. Clin. Oncol., 33, 307-313. http://dx.doi.org/10.1097/COC.0b013e3181d27361

Cassidy, J., Twelves, C., Van, C. E., Hoff, P., Bajetta, E., Boyer, M., ... Schilsky, R. L. (2002). First-line oral capecitabine therapy in metastatic colorectal cancer: a favorable safety profile compared with intravenous 5-fluorouracil/leucovorin. Ann. Oncol., 13, 566-575. http://dx.doi.org/10.1093/annonc/mdf089

Cassidy, J., Tabernero, J., Twelves, C., Brunet, R., Butts, C., Conroy, T., Debraud, F., ... Díaz-Rubio, E. (2004). XELOX (capecitabine plus oxaliplatin): active first-line therapy for patients with metastatic colorectal cancer. J. Clin. Oncol., 22, 2084-2091. http://dx.doi.org/10.1200/JCO.2004.11.069

Colucci, G., Gebbia, V., Paoletti, G., Giuliani, F., Caruso, M., Gebbia, N., ... Maiello, E. (2005). Phase III randomized trial of FOLFIRI versus FOLFOX4 in the treatment of advanced colorectal cancer: a multicenter study of the Gruppo Oncologico Dell'Italia Meridionale. J. Clin. Oncol., 23, 4866-4875. http://dx.doi.org/10.1200/JCO.2005.07.113 
de Gramont, A., Figer, A., Seymour, M., Homerin, M., Hmissi, A., Cassidy, J., ... Bonetti, A. (2000). Leucovorin and fluorouracil with or without oxaliplatin as first-line treatment in advanced colorectal cancer. J. Clin. Oncol., 18, 2938-2947.

Fuchs, C. S., Marshall, J., \& Barrueco, J. (2008). Randomized, controlled trial of irinotecan plus infusional, bolus, or oral fluoropyrimidines in first-line treatment of metastatic colorectal cancer: updated results from the BICC-C study. J. Clin. Oncol., 26, 689-690. http://dx.doi.org/10.1200/JCO.2007.15.5390

Gamelin, E., Gamelin, L., Bossi, L., \& Quasthoff, S. (2002). Clinical aspects and molecular basis of oxaliplatin neurotoxicity: current management and development of preventive measures. Semin. Oncol., 29, 21-33. http://dx.doi.org/10.1053/sonc.2002.35525

García-Alfonso, P., Muñoz-Martin, A. J., Alvarez-Suarez, S., Jerez-Gilarranz, Y., Riesco-Martinez, M., Khosravi, P., \& Martin, M. (2010). Bevacizumab in combination with biweekly capecitabine and irinotecan, as first-line treatment for patients with metastatic colorectal cancer. Br. J. Cancer, 103, 1524-8. http://dx.doi.org/10.1038/sj.bjc.6605907

Giacchetti, S., Perpoint, B., Zidani, R., Le, B. N., Faggiuolo, R., Focan, C., ... Lévi, F. (2000). Phase III multicenter randomized trial of oxaliplatin added to chronomodulated fluorouracil-leucovorin as first-line treatment of metastatic colorectal cancer. J. Clin. Oncol., 18, 136-147.

Goldberg, R. M., Sargent, D. J., Morton, R. F., Fuchs, C. S., Ramanathan, R. K., Williamson, S. K., ... Alberts, S. R. (2004). A randomized controlled trial of fluorouracil plus leucovorin, irinotecan, and oxaliplatin combinations in patients with previously untreated metastatic colorectal cancer. J. Clin. Oncol., 22, 23-30. http://dx.doi.org/10.1200/JCO.2004.09.046

Golfinopoulos, V., Salanti, G., Pavlidis, N., \& Ioannidis, J. P. (2007). Survival and disease-progression benefits with treatment regimens for advanced colorectal cancer: a meta-analysis. Lancet Oncol., 8, 898-911. http://dx.doi.org/10.1016/S1470-2045(07)70281-4

Grothey, A. (2003). Oxaliplatin-safety profile: neurotoxicity. Semin. Oncol., 30, 5-13. http://dx.doi.org/10.1016/S0093-7754(03)00399-3

Grothey, A., Sugrue, M. M., Purdie, D. M., Dong, W., Sargent, D., Hedrick, E., ... Kozloff, M. (2008). Bevacizumab beyond first progression is associated with prolonged overall survival in metastatic colorectal cancer: results from a large observational cohort study (BRiTE). J. Clin. Oncol., 26, 5326-5334. $\mathrm{http}: / / \mathrm{dx}$.doi.org/10.1200/JCO.2008.16.3212

Hospers, G. A., Schaapveld, M., Nortier, J. W., Wils, J., van, B. A., de Jong, R. S. et al. (2006). Randomised Phase III study of biweekly 24-h infusion of high-dose 5FU with folinic acid and oxaliplatin versus monthly plus 5-FU/folinic acid in first-line treatment of advanced colorectal cancer. Ann. Oncol., 17, 443-449. http://dx.doi.org/10.1093/annonc/mdj104

Hochster, H. S., Hart, L. L., Ramanathan, R. K., Childs, B. H., Hainsworth, J. D., Cohn, A. L., ... Mulder, N. H. (2008). Safety and efficacy of oxaliplatin and fluoropyrimidine regimens with or without bevacizumab as first-line treatment of metastatic colorectal cancer: results of the TREE Study. J. Clin. Oncol., 26, 3523-3529 http://dx.doi.org/10.1200/JCO.2007.15.4138

Hurwitz, H., Fehrenbacher, L., Novotny, W., Cartwright, T., Hainsworth, J., Heim, W., ... Kabbinavar, F. (2004). Bevacizumab plus irinotecan, fluorouracil, and leucovorin for metastatic colorectal cancer. $N$. Engl. J. Med., 350, 2335-2342. http://dx.doi.org/10.1056/NEJMoa032691

Hutchins, L. F., Unger, J. M., Crowley, J. J., Coltman, C. A., Jr., \& Albain, K. S. (1999). Underrepresentation of patients 65 years of age or older in cancer-treatment trials. N. Engl. J. Med., 341, 2061-2067. http://dx.doi.org/10.1056/NEJM199912303412706

Kim, T. W., Kang, W. K., Chang, H. M., Park, J. O., Ryoo, B. Y., Ahn, J. S., ... Kim, H-K. (2005). Multicenter phase II study of oral capecitabine plus irinotecan as first-line chemotherapy in advanced colorectal cancer: a Korean Cancer Study Group trial. Acta. Oncol, 44, 230-235. http://dx.doi.org/10.1080/02841860510029590

Kohne, C. H., De, G. J., Hartmann, J. T., Lang, I., Vergauwe, P., Becker, K., ... Van Cutsem, E. (2008). Irinotecan combined with infusional 5-fluorouracil/folinic acid or capecitabine plus celecoxib or placebo in the first-line treatment of patients with metastatic colorectal cancer. EORTC study 40015. Ann. Oncol., 19, 920-926. http://dx.doi.org/10.1093/annonc/mdm544 
Kozloff, M., Yood, M. U., Berlin, J., Flynn, P. J., Kabbinavar, F. F., Purdie, D. M., ... Grothey, A. (2009). Clinical outcomes associated with bevacizumab-containing treatment of metastatic colorectal cancer: the BRiTE observational cohort study. Oncologist, 14, 862-870. http://dx.doi.org/10.1634/theoncologist.2009 $-0071$

Koopman, M., Antonini, N. F., Douma, J., Wals, J., Honkoop, A. H., Erdkamp, F. L., .. Punt, C. J. A. (2007). Sequential vs combination chemotherapy with capecitabine, irinotecan and oxaliplatin in advanced colorectal cancer (CAIRO): a phase III randomised controlled trial. Lancet, 370, 135-142. http://dx.doi.org/10.1016/S0140-6736(07)61086-1

Krishnan, A. V., Goldstein, D., Friedlander, M., \& Kiernan, M. C. (2005). Oxaliplatin-induced neurotoxicity and the development of neuropathy. Muscle Nerve, 32, 51-60. http://dx.doi.org/10.1002/mus.20340

Macedo, L. T., Lima, A. B., \& Sasse, A. D. (2012). Addition of bevacizumab to first-line chemotherapy in advanced colorectal cancer: a systematic review and meta-analysis, with emphasis on chemotherapy subgroups. BMC Cancer, 12, 89. http://dx.doi.org/10.1186/1471-2407-12-89

Moehler, M., Sprinzl, M. F., Abdelfattah, M., Schimanski, C. C., Adami, B., Godderz, W., ... Kanzler, S. (2009). Capecitabine and irinotecan with and without bevacizumab for advanced colorectal cancer patients. World J. Gastroenterol, 15, 449-456. http://dx.doi.org/10.3748/wjg.15.449

Moosmann, N., von Weikersthal, L. F., Vehling-Kaiser, U., Stauch, M., Hass, H. G., Dietzfelbinger, H., ... Heinemann, V. (2011). Cetuximab Plus Capecitabine and Irinotecan Compared With Cetuximab Plus Capecitabine and Oxaliplatin As First-Line Treatment for Patients With Metastatic Colorectal Cancer: AIO KRK-0104-A Randomized Trial of the German AIO CRC Study Group. J. Clin. Oncol., 29, 1050-8. http://dx.doi.org/10.1200/JCO.2010.31.1936

Nalluri, S. R., Chu, D., Keresztes, R., Zhu, X., \& Wu, S. (2008). Risk of venous thromboembolism with the angiogenesis inhibitor bevacizumab in cancer patients: a meta-analysis. JAMA, 300, 2277-2285. http://dx.doi.org/10.1001/jama.2008.656

Okines, A., Puerto, O. D., Cunningham, D., Chau, I., Van, C. E., Saltz, L., ... Cassidy, J. (2009). Surgery with curative-intent in patients treated with first-line chemotherapy plus bevacizumab for metastatic colorectal cancer First BEAT and the randomised phase-III NO16966 trial. Br. J. Cancer, 101, 1033-1038. http://dx.doi.org/10.1038/sj.bjc.6605259

Park, S. H., Bang, S. M., Cho, E. K., Baek, J. H., Oh, J. H., Im, S. A., ... Lee, J. H. (2004). First-line chemotherapy with irinotecan plus capecitabine for advanced colorectal cancer. Oncology, 66, 353-357. http://dx.doi.org/10.1159/000079482

Payne, S. A. (1992). A study of quality of life in cancer patients receiving palliative chemotherapy. Soc. Sci. Med., 35, 1505-1509. http://dx.doi.org/10.1016/0277-9536(92)90053-S

Saltz LB, Clarke S, Díaz-Rubio E, Scheithauer W, Figer A, Wong R, ... Cassidy, J. (2008). Bevacizumab in combination with oxaliplatin-based chemotherapy as first-line therapy in metastatic colorectal cancer: a randomized phase III study. J. Clin. Oncol., 26, 2013-2019. http://dx.doi.org/10.1200/JCO.2007.14.9930

Scappaticci, F. A., Skillings, J. R., Holden, S. N., Gerber, H. P., Miller, K., Kabbinavar, F., ... Hurwitz, H. (2007). Arterial thromboembolic events in patients with metastatic carcinoma treated with chemotherapy and bevacizumab. J. Natl. Cancer Inst., 99, 1232-1239. http://dx.doi.org/10.1093/jnci/djm086

Scartozzi, M., Galizia, E., Chiorrini, S., Giampieri, R., Berardi, R., Pierantoni, C., ... Cascinu, S. (2009). Arterial hypertension correlates with clinical outcome in colorectal cancer patients treated with first-line bevacizumab. Ann. Oncol., 20, 227-230. http://dx.doi.org/10.1093/annonc/mdn637

Schmoll HJ, Arnold D. Update on Capecitabine in Colorectal Cancer. (2006). Oncologist, 11, 1003-9. http://dx.doi.org/10.1634/theoncologist.11-9-1003

Simpson, D., Dunn, C., Curran, M., \& Goa, K. L. (2003). Oxaliplatin: a review of its use in combination therapy for advanced metastatic colorectal cancer. Drugs, 63, 2127-2156. http://dx.doi.org/10.2165/00003495-200363190-00013

Sobrero, A., Ackland, S., Clarke, S., Perez-Carrion, R., Chiara, S., Gapski, J., ... Young, S. (2009). Phase IV study of bevacizumab in combination with infusional fluorouracil, leucovorin and irinotecan (FOLFIRI) in first-line metastatic colorectal cancer. Oncology, 77, 113-119. http://dx.doi.org/10.1159/000229787 
Therasse, P., Arbuck, S. G., Eisenhauer, E. A., Wanders, J., Kaplan, R. S., Rubinstein, L., ... Gwyther, S. G. (2000). New guidelines to evaluate the response to treatment in solid tumors. European Organization for Research and Treatment of Cancer, National Cancer Institute of the United States, National Cancer Institute of Canada. J. Natl. Cancer Inst., 92, 205-216. http://dx.doi.org/10.1093/jnci/92.3.205

Tournigand, C., Andre, T., Achille, E., Lledo, G., Flesh, M., Mery-Mignard, D., ... Gramont, A. (2004). FOLFIRI followed by FOLFOX6 or the reverse sequence in advanced colorectal cancer: a randomized GERCOR study. J. Clin. Oncol., 22, 229-237. http://dx.doi.org/10.1200/JCO.2004.05.113

Van Cutsem E., Hoff, P. M., Harper, P., Bukowski, R. M., Cunningham, D., Dufour, P., ... Schilsky, R. L. (2004). Oral capecitabine vs intravenous 5-fluorouracil and leucovorin: integrated efficacy data and novel analyses from two large, randomised, phase III trials. Br. J. Cancer, 90, 1190-1197. http://dx.doi.org/10.1038/sj.bjc.6601676

Van Cutsem E., Rivera, F., Berry, S., Kretzschmar, A., Michael, M., DiBartolomeo, M., ... Cunningham, D. (2009). Safety and efficacy of first-line bevacizumab with FOLFOX, XELOX, FOLFIRI and fluoropyrimidines in metastatic colorectal cancer: the BEAT study. Ann. Oncol., 20, 1842-1847. http://dx.doi.org/10.1093/annonc/mdp233

Vieitez, J. M., Carrasco, J., Esteban, E., Fra, J., Alvarez, E., Muniz, I., ... Jiménez, A. (2003). Irinotecan in the treatment of advanced colorectal cancer in patients pretreated with Fluorouracil-based chemotherapy: a study to determine recommendable therapeutic dosage. Am. J. Clin. Oncol., 26, 107-111. http://dx.doi.org/10.1097/00000421-200304000-00001

Yoo, P. S., Lopez-Soler, R. I., Longo, W. E., \& Cha, C. H. (2006). Liver resection for metastatic colorectal cancer in the age of neoadjuvant chemotherapy and bevacizumab. Clin. Colorectal Cancer, 6, 202-207. http://dx.doi.org/10.3816/CCC.2006.n.036 